\title{
Health care ethics: a pattern for learning
}

\author{
Donald Evans University College, Swansea
}

\section{Author's abstract}

The British Medical Association (BMA) has called upon the General Medical Council (GMC) to instruct all medical schools to provide identifiable and substantial courses on medical ethics in their undergraduate curricula. The author reviews a postgraduate scheme of study in the ethics of health-care and suggests that it could provide some useful guidelines for teaching the subject at the undergraduate level.

\section{Introduction}

The recent resolution of the British Medical Association calling on the General Medical Council to instruct medical schools to provide an identifiable and substantial course on medical ethics in the undergraduate curriculum is to be welcomed. At the same time it should call for careful consideration of how this might best be done. To plunge headlong into making space for the subject in timetables all over the country could be counter-productive if what is slotted into that space is ill-conceived and/or the personnel whose task it becomes to teach the subject are dragooned into the work or are unprepared for it.

A number of questions need to be answered. What should be the content of the syllabus? What should be its format and mode of presentation? Who should do the teaching? Precisely when should it be done? Should the course be examined and if so what should be the status of the examination? Should it be taught to medical students in isolation from other trainee health care professionals? In an effort to approach an answer to these questions I propose to describe a scheme of study in the University of Wales which is now moving into its third year. Whilst it is no doubt wider in scope than anything which the British Medical Association has in mind in that it constitutes a complete master's degree programme I am sure that a number of valuable lessons can be learned from it.

\section{Key words}

Teaching health care ethics.

\section{The need for such teaching}

In case there are those in the medical schools who have yet to be persuaded of the need for such teaching in the preparation of young men and women for the medical profession it is worth noting that the Welsh scheme originated directly from requests made to a philosopher by experienced medical practitioners in both hospital and general practice for some lectures on medical ethics. They were daily at the sharp end of decision-making in their work but felt that the training they had received did not equip them to think through the ethical dimensions of problems presented by the rapid development of high-tech medicine and the economic squeeze on the health service. The need was to become even more evident when a curriculum was developed and the part-time scheme of study was advertised. In response to one day's advertising in three national newspapers, the British Medical Fournal and the Nursing Times more than six hundred enquiries were received from all parts of the British Isles. These resulted in more than two hundred firm applications within six weeks of the advertisement. The response was unexpected and overwhelming. The range and quality of the applicants was equally impressive, revealing how general are the worries which lie at the heart of the ethics of health-care. The list included hospital consultants from the disciplines of general surgery, anaesthetics, plastic surgery, obstetrics, venereology, psychiatry, pathology, radiology, medical physics, geriatrics, dental surgery and medicine. Other medical personnel included general practitioners, clinical psychologists, medical officers from the Department of Health and Social Security (DHSS) and from local health authorities, industrial doctors and community physicians. The list also included directors of nursing studies, senior tutors and tutors, health visitors, medical social workers, hospital administrators, academics from university and polytechnic departments of haematology, law and social science, research pharmacists, hospital pharmacists, retail pharmacists and pharmaceutical company executives, a physiotherapist, a coroner, a medical journalist, the director of a national charity, a priest and the headmaster of a school for maladjusted children. About ninety per cent of the one hundred or 
so candidates accepted on the course are self-financed and many of them have to use their holiday quotas for two years in order to pursue the scheme of study. Such is the level of motivation, which is in part a reflection of the pressing character of the need for the provision of teaching in the area of health-care ethics. After two years of study the class of very busy health-care professionals has shown a drop-out rate of less than four per cent per annum and those who have withdrawn have done so for reasons of changes in personal and professional circumstances. A class of comparable size and quality is due to begin the next course which commences in October 1987. It is but one of a number of postgraduate schemes offered at the Centre for the Study of Philosophy and Health Care.

The need for the teaching of the ethics of health-care may not be so obvious to the young and ambitious undergraduate who is naturally concerned to qualify for the career of his or her choice. The experience of the Medical Groups shows that there is a healthy minority interest in these matters amongst students but it is a minority interest nevertheless. It would be surprising if the degree of motivation to be found initially amongst those who had not come up against many of the difficulties under discussion were found to equal that of those who had had to grapple with them at first hand. This difficulty does not, of course, diminish the desirability of making such teaching a part of the curriculum. Whilst it will not be possible to put old heads on young shoulders it will certainly be possible to alert students to the moral dimensions of the work they are about to embark upon. And this in turn will shape their attitudes and expectations in ways which can only make them better doctors, nurses or whatever.

\section{The interdisciplinary character of the study}

One of the outstanding features of the University of Wales scheme has been the wide representation of health-care professionals in the class. This arose largely out of reservations about the notion of medical ethics which surfaced in discussions between philosophers at University College, Cardiff and professors at the University College of Medicine. Indeed it was one of the latter who suggested widening the scope of the scheme by adopting the label of the Philosophy of Health-Care. Thus the scheme was not targeted solely at medical personnel. This move has turned out to be even more rewarding than was at first envisaged. It has facilitated full and frank discussions across the professional boundaries which have become fairly rigid in the field of health-care provision. It has also revealed important and interesting questions at the interface of the professions. It has shown too that most moral dilemmas run across these lines of demarcation and that if they are capable of some kind of resolution in practice then it has to be one which takes account of all the people involved - both the carers and the cared for. This is not to say that there are not important distinctions to be made between the responsibilities and so on of these various categories of professional, nor that each profession might not be able to offer a unique perspective upon many of the issues under discussion. Candidates on the course, however, would agree that the possibility of exchange between the professions offered by the scheme has enriched and informed their discussions. In fact many have admitted that it is the first time that they have been parties to such an exchange despite many years involvement in the provision of health-care.

Then what of undergraduate teaching? I simply make the tentative suggestion that it would be worth considering a similar mix of prospective professionals in teaching at this level. There are some obvious advantages to be gained. For example it would be good to produce contact of this sort in the formative years of the professionals as part of the training which would shape their perceptions of other professions as well as their own, professions with which they will have much to do in their subsequent careers. It is generally agreed that an inward-looking protectionist attitude towards any of the professions involved in providing healthcare does nothing but compound the moral problems thrown up by such provision. The mix has worked very well in numbers of Medical Groups throughout the country and a healthy precedent is already well established. How much more impressive would the move be if positively adopted by the medical schools.

\section{The format of the teaching}

There is little doubt that part of the success of the innovation in Wales is due to the logistics of the course. From the outset it was clear that those who wished to be involved would be people who were already very busy in their professions. Some means had to be found to enable them to accommodate the teaching in their crowded timetables. The idea of a weekly meeting was entertained, but only briefly. Such an arrangement would have automatically limited the availability of the scheme to those within easy striking distance of the centre. It would also have been difficult to find any one-day or half-day in each week which was convenient for all potential class members.

Thus the idea of using residential conferences was employed. Each candidate attends five residential conferences, each of three days duration, over a period of two years. Due to the size of the class these are duplicated and the class is divided into two parts of almost identical constitution in terms of the professional roles of the members. These conferences are intensive teaching sessions made up of formal lectures, small group discussions and plenary discussions. At each conference one or two areas of the syllabus are opened up and explored. Between conferences, by means of more detailed examination of the literature and with the help of small group seminars in the regions, students prepare written assignments on the area of the syllabus introduced at the previous conference. This format has worked extremely well in 
that it has enabled people who are heavily committed in their work schedules to timetable small blocks of time well in advance. It has also spread the catchment area all over England, Scotland, Wales and the Channel Islands.

What the format should be at the undergraduate level is a more open question. For the problems of geography and availability do not arise there. Nevertheless there is still something to be said for the possibility of packaging the teaching into identifiable blocks rather than spreading it thinly throughout the undergraduates' careers. First there is the obvious difficulty of timetabling, especially if the classes are to be shared by students of other disciplines as suggested above. This is more easily overcome by blocking out a period in each of three or four years - even a whole week in each. No doubt this suggestion will raise howls of protest from teachers of other subjects in the curriculum who will feel that they cannot possibly do with an hour less on the timetable to deal with the matters covered in their curricula. However, even four weeks out of one hundred and fifty in the undergraduate's career constitutes less than 2.7 per cent of the timetable. Anything less would hardly merit the British Medical Association's description of a substantial and identifiable course. Second, there is the advantage of the possibility of sustained discussion in these areas, facilitating a genuine exchange of views and immersion in the material. One hour every week would not afford this continuity. Third, there is the possibility of using invited guests for special feature sessions - leading names in given areas - which produce challenge and variety. This has produced a favourable response in the Cardiff scheme. Such visitors need more than the odd hour to make maximum impact. Their availability over two days for discussion and questioning could be accommodated by means of the block-teaching format.

\section{The question of examination}

The question of whether to examine students' performance never arose in the context of the postgraduate scheme described above. It was automatically part of a scheme the end-point of which was the award of a degree. However, the question of how the examination should be structured was given careful consideration. The mode of examination ultimately agreed upon was that the course essays would be assessed and would constitute 25 per cent of examination. These must all be completed during the first two years of study, at the end of which one threehour examination paper is sat. This constitutes a further 25 per cent of the final assessment. Finally candidates submit a twenty-thousand word dissertation on a topic of their choice, subject to the approval of their supervisor. This extended piece of work must be completed within two years of the written paper and will constitute the final 50 per cent of the overall assessment. At this stage it is expected that candidates will bring the expertise gained in the first two years of study to bear upon the areas of special interest and experience from which they are drawn. Given the quality of work so far produced it is firmly believed that the research dissertations will together make a valuable contribution to the literature of the subject.

Clearly the question of whether or not to examine undergraduates who are taught health-care ethics is one which will arise and which will probably be the source of some disagreement. It may be tempting to take the easy option and regard the teaching as the provision of general background which it will be hoped will interest students but not be of fundamental importance as part of their qualifications as doctors, nurses, administrators, pharmacists or whatever Those who espouse such a view will naturally oppose what may be regarded as the production of unnecessary impediments to gaining professional qualifications. On the other hand, those who take a more serious view of the need for such a thread in the fabric of medical training, as reflected in the resolution of the British Medical Association, will be wary at the suggestion of dispensing with examination. They will have good reasons to oppose the suggestion. First, it will be seen as a reflection of the importance which the teaching institutions attach to the subject itself. Second, it is a fairly well attested fact that unless a course is examinable and the examination in turn counts foo something then undergraduates will not treat seriously, no matter what the sponsoring institution $\frac{\bar{Q}}{\mathrm{\sigma}}$ professed views of the course's importance happen to be. I would therefore favour the suggestion that the examination have the status of a qualifying examination.

This leaves open the question of how the examination should be structured. There is much to be said for using the continuous assessment model, for this will ensure that a number of serious pieces of course work will be completed during the student's career. What more could be expected of an examination in this subject than that it help concentrate the student's mind on a series of important questions?

\section{The content of the syllabus}

The syllabus of the postgraduate scheme is wideranging. Beginning with an introduction to the nature of of ethical theories and philosophical reflection it $N$ extends over the following areas of health-care $N$ provision which throw up conceptual and ethical questions:

Administration of health-care: Rights and justice, $\stackrel{\mathcal{D}}{\rightarrow}$ Third-world patterns and problems, private and public provision, allocation of scarce resources, the National Health Service.

The professional-patient relation: Professional $\stackrel{\odot}{\odot}$ ethics, rival conceptions, medicine and criminal justice. 
Patient perspectives: Consent (informed, proxy and coerced), choice (place, personnel, treatment), information (the right to know), patients or persons (holistic medicine, counselling, sociobiology).

Reproductive medicine: The Warnock Report abortion and contraception, genetic engineering and counselling, conception (IVF, cloning, freezing of sperm, oocyte and embryo, surrogacy), embryo research.

Medical research: Use of patients, voluntary healthy subjects and animals, consent, role conflict of healer and researcher.

Death and treatment of the dying: Definition of death, euthanasia, prolongation of life, the hospice movement.

Health and disease: Preventive medicine, community medicine, illness and disease, nuclear war and medicine, alternative medicine.

Drugs: Prescribing, addiction and abuse, testing, marketing, legal perspectives.

Mental Illness: Identity of mental illness, abuse of psychiatry, psychiatric medicine and autonomy, McNaughton rules, insanity and responsibility.

It is important to notice that the syllabus is not concerned with matters of professional etiquette nor with such topics as the legality of death certificates, except where such issues themselves figure in the context of the morality of the particular management of particular patients or of decision-making. In this sense it is quite distinct from much that has gone under the description of 'medical ethics' in the past.

It is of crucial importance that any slot made for the teaching of the ethics of health-care at an undergraduate level be similarly distinct from an induction into the niceties of medical practice and inhouse professional codes of behaviour, which may be more or less connected with the issues of greater moment listed above. This is not to say that there is no such thing as a professional ethic with which the student should become familiar. It is to say, however, that any and every code of practice, no matter to which health-care profession it attaches, should be subjected to a more general scrutiny in any substantial course on the ethics of health-care. There is already a considerable literature on the issues listed above and it is growing rapidly. Thus there is no shortage of suitable resources to assist students in the study of the subject.

\section{Who should do the teaching?}

The Welsh scheme is sponsored by the Centre for the Study of Philosophy and Health Care in collaboration with the University of Wales College of Medicine. This collaboration is reflected in the personnel involved in the teaching. The conferences are convened and planned by the philosophers who also set, annotate and assess the assignments and conduct the regional seminars. None of the philosophers regularly involved is medically qualified. Their training is in conceptual analysis and philosophical argument. However, this philosophical input is tempered and informed by expert contributions from health-care professionals at the teaching conferences. In addition to numbers of professors from the College of Medicine this group of teachers also includes Dr Raanan Gillon, Mr Patrick Steptoe and Professor Eric Wilkes. Baroness Warnock and Professor Alan Maynard are amongst other distinguished visiting scholars involved in the scheme.

By providing instruction and guidance in philosophical analysis the philosophers act as a catalyst for class discussion. The class is extremely wellinformed about the various areas of the syllabus and it has proved possible to engage in serious philosophical discussion without conducting a tour-de-force of the history of moral philosophy.

Why should philosophers figure so prominently in the teaching of the ethics of health-care? This question has occurred to numbers of health-care professionals who feel that the philosopher's role constitutes an unwarranted intrusion of amateurs into an area where the experienced professionals are capable of putting their own house in order, if ordering is thought to be necessary at all. There are good reasons why philosophers should be so involved. First, some of the fundamental issues are conceptual in character. Think, for example, of the question of when human life begins - a consideration crucial to any responsible discussion of embryo research, abortion, genetic engineering and the management of handicapped neonates. Similar clusters of problems surround the question of when life ends, the concept of informed consent and so on. Second, the grammar or logic of moral discourse is something about which many who are faced with moral dilemmas in providing health-care are not clear. Third, it is generally beneficial that someone other than a professional health-carer play such a role to ensure that the study is wider than that of any particular professional ethic as observed above.

Some of the resistance which the medical schools might feel to the employment of philosophers and other non-medical personnel such as economists and lawyers might be due to the character of much that has been written by such people about medical ethics. Philosophers disagree as much about how much the study of their subject can achieve as they do about other things. Whilst many, if not most, who have written on the ethics of health-care have felt that philosophy is capable of providing substantive answers to many of the moral problems facing health-care practitioners, others would disagree. In the University of Wales scheme the philosophers are predominantly more modest about what they think philosophical reflection can achieve in this area. However, whilst it might be irksome for the qualified health-care professional to be told by others what it is right for him or her to do, the reasons given for such conclusions by the philosophers concerned demand due consideration. Whichever persuasion the philosopher 
has about the scope of his subject, his object is to get clear about the issues in question and to help those who are willing to listen to make as reasonable and responsible decisions as possible in their practice. It is proper nevertheless for the professionals to demand that such reflection be not conducted in a vacuum. In the University of Wales scheme care is taken at all stages to guarantee that professional input informs the philosophical discussion lest the scheme be accused of being concerned with problems of fantasy and science fiction rather than with the realities with which those involved with health care have to struggle.

Donald Evans FP BA PhD is Director of the Centre for the Study of Philosophy and Health Care at University College, Swansea. He is also Associate Director of the Institute of Medical Ethics.

\section{News and notes}

\section{Philosophical ethics in reproductive medicine}

A conference on philosophical ethics in reproductive medicine will be held at Leeds University from April 18-22, 1988.

Speakers have been invited from the United States of America, Britain and Europe and there will be free communication sessions and poster displays representing the work of many experts in the field.
Those wishing to submit abstracts should contact the Conference Organiser, Mrs C P Shirley, Department of Adult and Continuing Education, The University, Leeds, LS2 9JT, UK for the appropriate form.

All abstracts should be submitted by 1 December, 1987. 